\title{
Region-specific alleles of the Drosophila segmentation gene hairy
}

\author{
Ken Howard, ${ }^{1}$ Phil Ingham, ${ }^{2,4}$ and Chris Rushlow ${ }^{3}$ \\ ${ }^{\mathrm{I}}$ Howard Hughes Medical Institute, Department of Neurobiology and Behavior, Columbia University, New York, New York \\ 10032 USA; ${ }^{2}$ Medical Research Council, Laboratory of Molecular Biology, University Medical School, Cambridge CB2 2QH, \\ UK; ${ }^{3}$ Department of Biological Sciences, Columbia University, New York, New York 10027 USA
}

\begin{abstract}
An essential step in the Drosophila segmentation mechanism is the expression of the pair-rule gene hairy in a periodic pattern in the blastoderm. In this paper we describe four regulatory hairy mutations. Using in situ hybridization, we show that these mutations cause alterations in the normal pattern of hairy expression. The new patterns are partial versions of the wild-type pattern and indicate that there are regulatory sequences associated with hairy that respond to distinct cues in different parts of the blastoderm. This suggests that a major function of hairy is to decode a prepattern consisting of complex cues (probably generated by the coordinate and gap classes of segmentation genes) into a simple periodic pattern. We have located the mutations on the DNA map of the hairy gene. They identify a $5^{\prime}$ region of $\leqslant \mathbf{2 0} \mathbf{k b}$ necessary for this decoding function.
\end{abstract}

[Key Words: Drosophila; segmentation; pair-rule; cis-regulation; prepattern; decoding]

Received March 29, 1988; revised version accepted June 6, 1988.

A genetic analysis of the formation of the segmental pattern of the Drosophila larva has revealed a hierarchy in which maternally acting coordinate genes and zygotically acting genes of the gap, pair-rule, and segment polarity classes (Nüsslein-Volhard and Wieschaus 1980) cooperate to generate the final periodic pattern. In general, it seems that information is transferred from one class of genes to the next and that the initial asymmetries generated by the coordinate genes are elaborated into a periodic pattern in the process (for review, see O'Farrell and Scott 1986; Akam 1987; Gaul and Jackle 1987; Nüsslein-Volhard et al. 1987; Scott and Carroll 1987). The first manifestation of periodicity during this process is the expression of pair-rule genes in patterns with a repeat unit of two segmental primordia (Hafen et al. 1984; Carroll and Scott 1985; Ingham et al. 1985a; Ish-Horowicz et al. 1985; Weir and Kornberg 1985; Harding et al. 1986; Kilcherr et al. 1986; Macdonald et al. 1986; Frasch et al. 1987). There is a hierarchy within the pair-rule class (Nüsslein-Volhard et al. 1985; Carroll and Scott 1986; Howard and Ingham 1986; Ingham and Martinez-Arias 1986; Martinez-Arias and White 19881, and three of these genes, hairy, runt, and even-skipped (the 'primary' pair-rule genes), have positions at the top of this hierarchy, with others, such as fushi tarazu (ftz), being subordinate to them.

An important question is how the initial periodicity is generated. One possibility is that some or all of the pair-

${ }^{4}$ Current address: Imperial Cancer Research Fund, Developmental Biology Unit, Department of Zoology, University of Oxford, Oxford OX1 3PS, UK. rule genes are components of a reaction-diffusion mechanism that generates the periodicity (Turing 1952). Alternatively, primary pair-rule genes may be responding to a set of cues appropriately spaced in a prepattern (Stern 1968). If this is so and if the cues are different in different parts of the blastoderm, it should be possible to isolate mutations in the regulatory regions of these genes that affect the response to particular cues while leaving others unaffected. Here, we describe four such hairy mutations: $h^{k 1}, h^{m 3}, h^{m 7}$, and $h^{m 8}$. These mutants express partial versions of the normal hairy pattern at the blastoderm stage of development. There are corresponding localized changes in the pattern of expression of $f t z$ and in the larval cuticle, indicating that the transcripts observed are functioning in the places where they are produced. The phenotypes fall into a series in which the order of the alleles is $h^{k 1}, h^{m 8}, h^{m 7}$, and $h^{m 3}$, with $h^{m 3}$ being closest to the wild-type. We have mapped the lesions associated with these alleles and find that they remove progressively more of the regulatory region so that $h^{k 1}$, the strongest of the alleles, has the least 5' DNA remaining intact. The $5^{\prime}$ limit of the regulatory region lies between -14.9 and $-19.8 \mathrm{~kb}, 5^{\prime}$ to the start of transcription, and is defined by another hairy allele, $h^{\text {r47 }}$, which does not produce defects in segmentation and affects only the adult function of hairy (Ingham et al. 1985b; Ish-Horowicz et al. 1985).

We conclude that a major function of hairy is to decode a complex set of cues into a periodic pattern. The simplest molecular mechanism would be for the regulatory region of hairy to consist of a set of discrete elements that respond independently to distinct cues present in the different parts of the blastoderm. 


\section{Results}

The wild-type pattern of hairy expression in a cellularizing blastoderm embryo, at late stage 14 of Foe and Alberts (1983) is shown in Figure la. This pattern consists of eight regions of expression: region 0 , which is confined to the anterodorsal part of the blastoderm, and a series of seven stripes, regions 1-7 (Ingham et al. 1985a; Ish-Horowicz et al. 1985). These correspond approximately with the primordia for the labrum (region 0 ) and parasegments $1,3,5,7,9,11$, and 13 (stripes $1-7$ ). The patterns of hairy expression seen in cellular blastoderm embryos mutant for $h^{k 1}, h^{m 8}, h^{m 7}$, and $h^{m 3}$ are also shown in Figure 1. In each case, the pattern can be described simply as a partial version of the wild-type pattern, with particular regions present and others reduced in strength or entirely absent. Although this description is not completely adequate /cases were it fails are described below), it is useful to picture the basic features of these mutants: The least extreme of the region-specific hairy alleles, $h^{m 3}$, develops a pattern that resembles a wild-type allele, except that stripes 3 and 4 fail to form (Fig. lb). The next allele in the series, $h^{m 7}$, produces transcripts in regions $0,1,2$, and 5 . The level of transcript in stripe 2 is significantly lower than that in the other regions (Fig. 1c). After this comes $h^{m 8}$, which also produces transcripts in regions $0,1,2$, and 5, although the level of transcript in stripe 2 is lower than that in $h^{m 7}$ and can only be detected at the beginning of gastrulation (Fig. 1, e and f). In the most extreme of the alleles, $h^{k 1}$, hairy transcripts are present only in region 0 , and the seven stripes characteristic of the wild type do not develop (Fig. 1g). Another hairy allele, $h^{\text {r47 }}$, disrupts the later function of the gene but does not disturb segmentation (Ingham et al. 1985b; Ish-Horowicz et al. 1985). This allele produces hairy transcripts in a normal pattern in the blastoderm (data not shown).

There are some aspects of the expression patterns of the two weaker mutants, $h^{m 3}$ and $h^{m 7}$, which do not conform to the simple description of partial versions of the normal hairy pattern. In both instances, we see a more diffuse pattern of transcript distribution. This is easily seen in the case of $h^{m 3}$ : The stripes that do form fail to resolve as sharply as they do in wild-type embryos (Fig. lb). For $h^{m 7}$, the difference is more subtle: we see a much higher background signal in the $h^{m 7}$ blastoderms than we do in other material (see Fig. $1 \mathrm{~h}$; cf. the signal in the mutant embryo with the wild-type sibling lying close to it on the same slide). In this case, our data do not allow us to distinguish between a very low level of periodic expression of hairy or genuine uniform expression.

The striped pattern of hairy expression forms in the middle of the final cell cycle of the blastoderm. Before this time, hairy transcripts are present more or less uniformly at low levels throughout wild-type embryos (Ingham et al. 1985a; Ish-Horowicz et al. 1985). It has been proposed that regulation by global activation followed by local repression might apply to many segmentation genes, including hairy (Edgar et al. 1986). In view of this, it would be interesting to know how the regionspecific patterns that we see arise. One observation sug- gests that the stripes observed arise by local activation. Early stage $14 h^{m 8}$ mutant embryos show only two regions of expression, the antero-dorsal (region 0 ) and stripe 1 (Fig. 1d). We infer that the later formation of stripe 5 and of the weak stripe 2, as shown in Figure 1, e and $f$, is due to local activation rather than global activation followed by local repression. Unfortunately, we cannot confidently distinguish mutant embryos from their wild-type siblings at earlier stages of development; therefore, we have not pursued the question of the early development of these patterns further.

\section{Consequences of hairy expression in the mutants}

We have examined two aspects of the phenotypes of the region-specific mutants that would be expected to reflect hairy expression: the pattern of $f t z$ transcripts in the blastoderm (Fig. 2) and the cuticle secreted at the end of embryogenesis (Fig. 3). In both cases, it seems that the patterns are composed of a mixture of wild-type (in the regions where hairy is expressed) and mutant (where it is not) phenotypes, indicating that the transcripts observed are functioning in the blastoderm.

ftz expression phenotypes The pattern of expression of the pair-rule gene $f t z$ is dependent on hairy activity (Carroll and Scott 1986; Howard and Ingham 1986). Although certainly something of a simplification, the changed pattern may be thought of in terms of a failure of hairy to repress $\mathrm{ftz}$ (for discussion, see Howard and Ingham 1986). Assuming that hairy acts locally, one would expect that the expression of hairy stripe 5 , e.g., which lies approximately between $\mathrm{ftz}$ stripes 4 and 5 , would promote the resolution of these two $\mathrm{ftz}$ stripes from one another. In the absence of hairy stripe 5, these two $f t z$ stripes would tend to merge. With the exception of $h m 7$, the $f t z$ patterns we see appear to be a mosaic of wild-type and mutant patterns as though hairy were indeed acting locally (Fig. 2).

In $h^{m 3}$, hairy regions 3 and 4 do not form; consequently we see a broad region of $f t z$ expression that seems to consist of the fusions of $f t z$ regions $2-4$ (Fig. 2b). In the case of $h^{m 7}$, the $f t z$ pattern is resolved more clearly than one might expect. It shows the resolution of $f t z$ stripes 1 from 2 and 4 from 5 expected to be caused by hairy regions 2 and 5 , but in addition, the other $f t z$ bands are better resolved than is typical in hairy nulls (Fig. 2c). This is consistent with the finding of low levels of hairy expression in this mutant (mentioned above). In $h^{m 8}$ mutants, hairy stripe 5 is expressed, and as a consequence, $f t z$ stripes 4 and 5 are resolved from one another (Fig. 2d). The pattern of $f t z$ expression in $h^{k 1}$ is indistinguishable from the pattern in hairy nulls.

Cuticle phenotypes The cuticle of the wild-type larva is shown in Figure 3a; the ventral denticle belts marking the anterior portion of each of the three thoracic (T1-T3) and eight abdominal (A1-A8) segments can be seen. The dorsal and head structures are not easily discernible in these micrographs. An example of the null phenotype of hairy is shown in Figure $3 \mathrm{f}$. In this case, the phenotype is fairly regular, showing a deletion of 

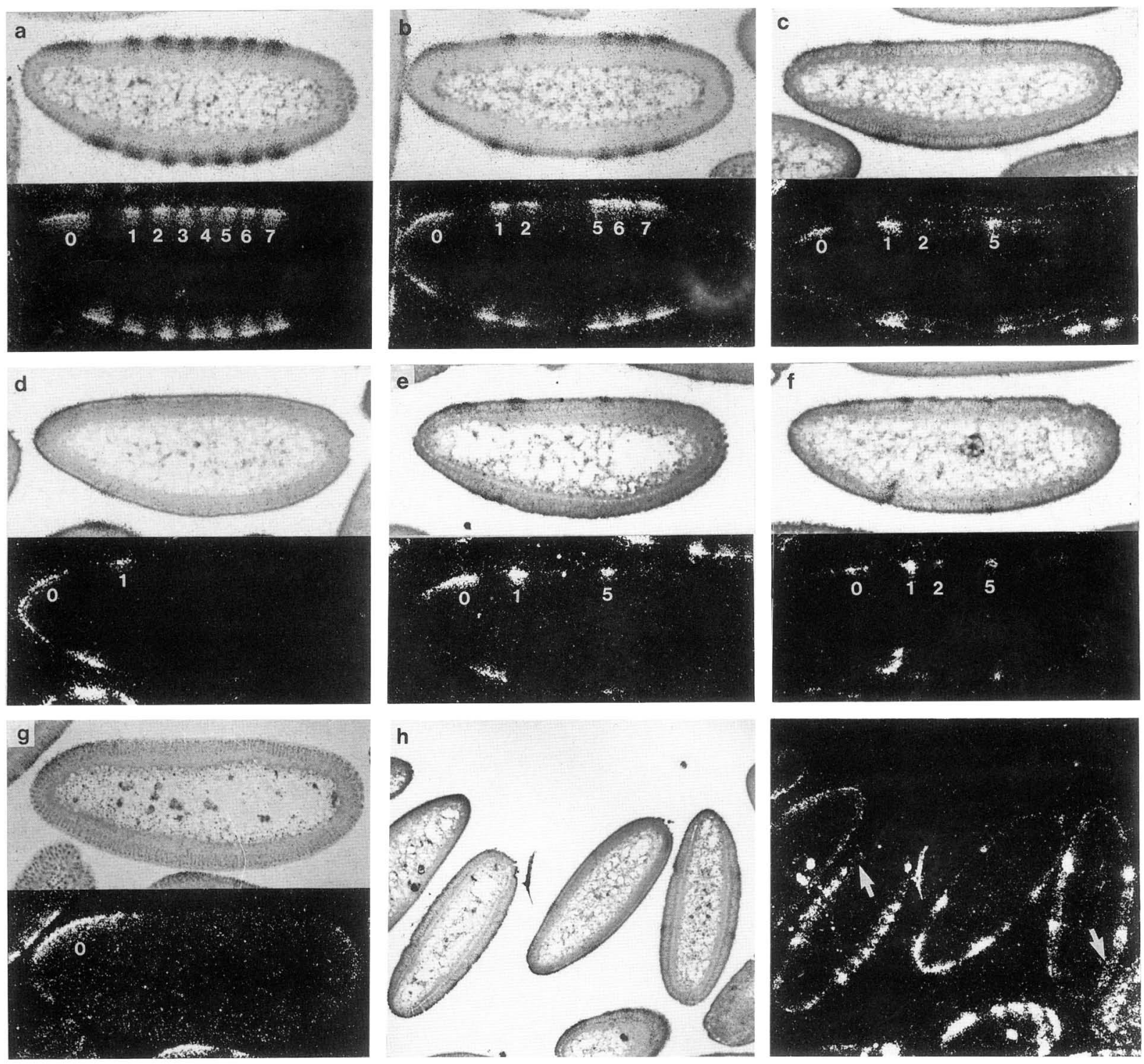

Figure 1. hairy expression in the region-specific alleles. $(a-h)$ In situ hybridizations to blastoderm-stage embryos. Except for $h$, the upper panels are bright-field views of the same subject shown in dark field below. In $h$, the bright- and dark-field images lie on the left and right rather than on the top and bottom. $(a)$ Wild type; $(b) h^{m 3} / D f(3 L) h^{i 22} ;(c) h^{m 7} / h^{m 7} ;(d) h^{m 8 / h^{m 8}} ;\left|e h^{m 8} / h^{m 8} ;(f) h^{m 8} / h^{m 8} ;\right| g \mid$ $h^{k 1} / h^{k 1} ;(h) h^{m 7} / h^{m 7}$ and wild-type embryos lying together on the same slide. $(a)$ The wild-type pattern consists of eight regions of expression, an antero dorsal patch $(0)$ and seven stripes $(1-7)$. $(b)$ In $h^{\mathrm{m} 3}$, the pattern shows two changes: loss of stripes 3 and 4 and a noticeable broadening of the remaining stripes. $(c) h^{m 7}$, regions 0,1 , and 5 are expressed at approximately wild-type levels; region 2 is at a significantly lower level (see also $h) .(d-f)$ A series of $h^{m 8}$ mutant embryos. $(d)$ Relatively early in cycle 14 , only region 0 and stripe 1 are visible. $(e)$ Later in cycle 14 , stripe 5 becomes apparent. $(f)$ Only as gastrulation begins does stripe 2 become visible. $(g)$ in $h^{k 1}$, only the antero dorsal region 0 is expressed. $\left(h \mid h^{m 7}\right.$ shows a significantly higher background signal in the 'off' regions than wild type does [cf. the posterior region (arrow) in the $h^{m 7}$ mutant embryo on the right, with the posterior off region (arrow) in the wild-type embryo on the left $]$. In all cases, the probe was labeled with ${ }^{35}$ S; exposure times were between 7 and 10 days.

pattern elements approximating alternate parasegmental units. For instance, the posterior part of $\mathrm{Al}$ and the anterior part of A2 (parasegment 7) are missing. Loss of hairy function does not always produce such a regular phenotype: Often, the deletions are more extensive and the fused segments themselves seem to fuse (Holmgren 1985; Ingham et al. 1985b; Ish-Horowicz et al. 1985). In other cases, the deletions are less extensive (Howard and Ingham 1986). The cuticle secreted by the region-spe- cific hairy mutants is shown in Figure $3, \mathrm{~b}-\mathrm{e}$. The two weaker alleles, $h^{m 3}$ and $h^{m 7}$, have very regular phenotypes, whereas $h^{m 8}$ and $h^{k 1}$ show far more variability. The cuticle presented in Figure 3 is representative of the phenotype of each of the alleles.

In $h^{m 3}$ mutant cuticle, the third thoracic and second abdominal denticle belts fail to form in animals that otherwise appear to be wild type (Fig. $3 b$; also see Ingham et al. 1985b). The primordia from which these 

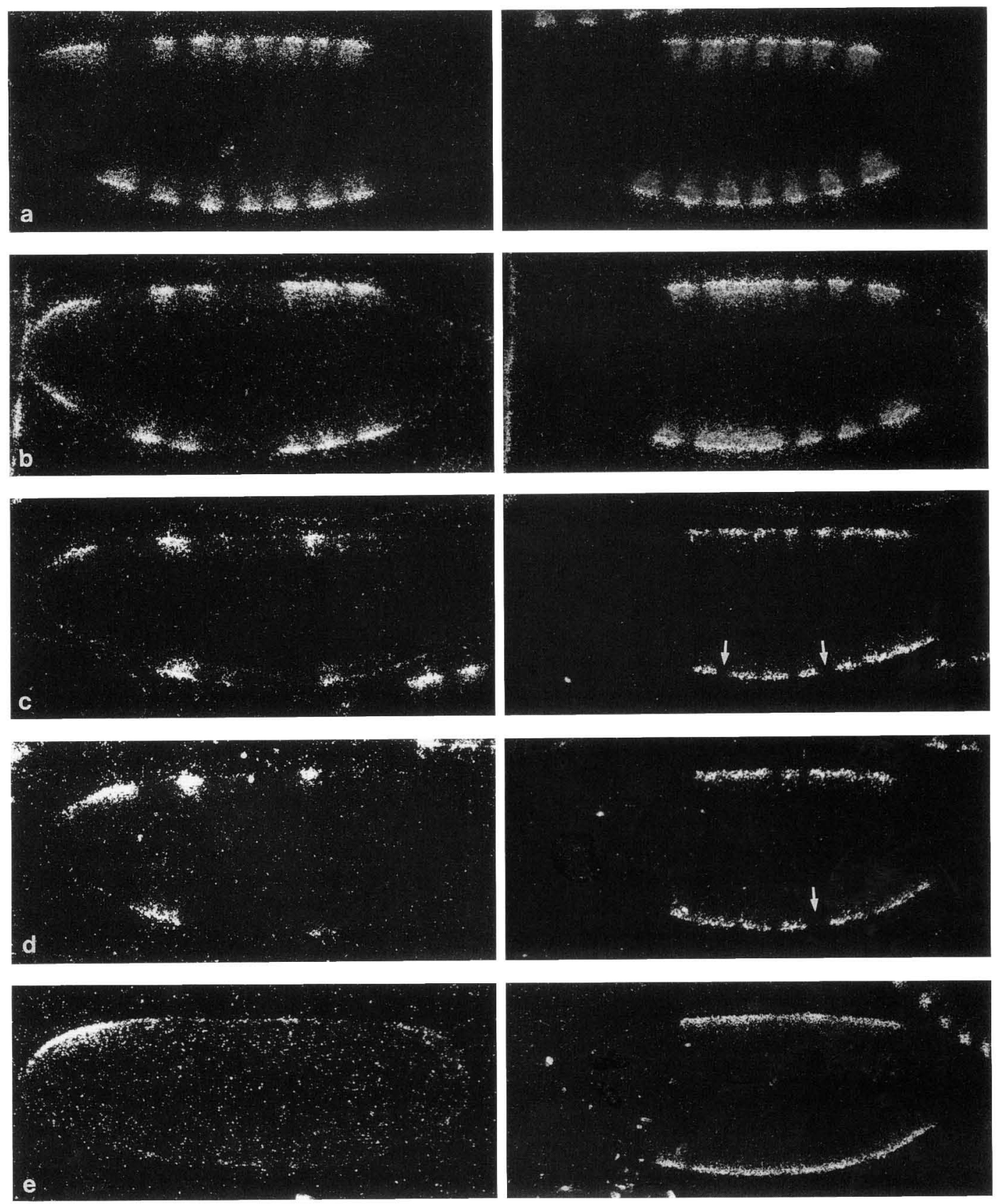

Figure 2. $f t z$ and hairy in the region-specific hairy mutants. $(a-e)$ In situ hybridizations to blastoderm-stage embryos. (a) Wild type; (b) $h^{m 3} / D f(3 L) h^{i 22} ;(c) h^{m 7} / h^{m 7} ;(d) h^{m 8} / h^{m 8}$; $(e) h^{k 1} / h^{k 1}$ (left) hairy signal, (right) ftz expression. Except for the data in $e$, each pair is of adjacent sections. (a) The wild-type hairy (left) and ftz (right) patterns. (b) Note the fusion of $f t z$ stripes $2-4$ in the $h^{\mathrm{m} 3}$ mutant. These bands normally lie approximately between the third and fourth stripes of hairy expression. $(c) \operatorname{In} h^{m 7}$, the $f t z$ stripes 1 and 2 and 4 and 5 are clearly resolved (arrows). Note also that the other $f t z$ stripes are quite distinct. This is not typical of $f t z$ expression in hairy nulls, and we attribute it to the low level of expression of hairy seen outside regions $0,1,2$, and 5 in $h^{m 7}$. (d) ftz stripes 4 and 5 are resolved in $h^{m 8}$ mutants (arrow). The resolution of regions 3 and 4 seen in this example frequently occurs in hairy nulls (Howard and Ingham 1986). (e) An example of a strongly altered $f t z$ pattern in $h^{k 1}$. All material was probed with ${ }^{35} S$-labeled probes, except for the $f t z$ hybridizations in $c$ and $d$, which employed ${ }^{3} \mathrm{H}$ probes.

denticles arise are associated with hairy stripes 3 and 4 , which are absent from the mutant blastoderm. Homozygous $h^{m 7}$ mutants almost always form at least a partial fourth abdominal denticle belt (Fig. 3c). The primordia for this structure is associated with hairy stripe 5 , which forms almost normally in $h^{m 7}$ mutants. We also see some enlargement of the ventral arms of the cephalopharyngeal skeleton in $h^{m 7}$ compared with hairy null animals. We attribute this to the expression of hairy in stripe 1 in the mutants; this stripe of hairy expression is 

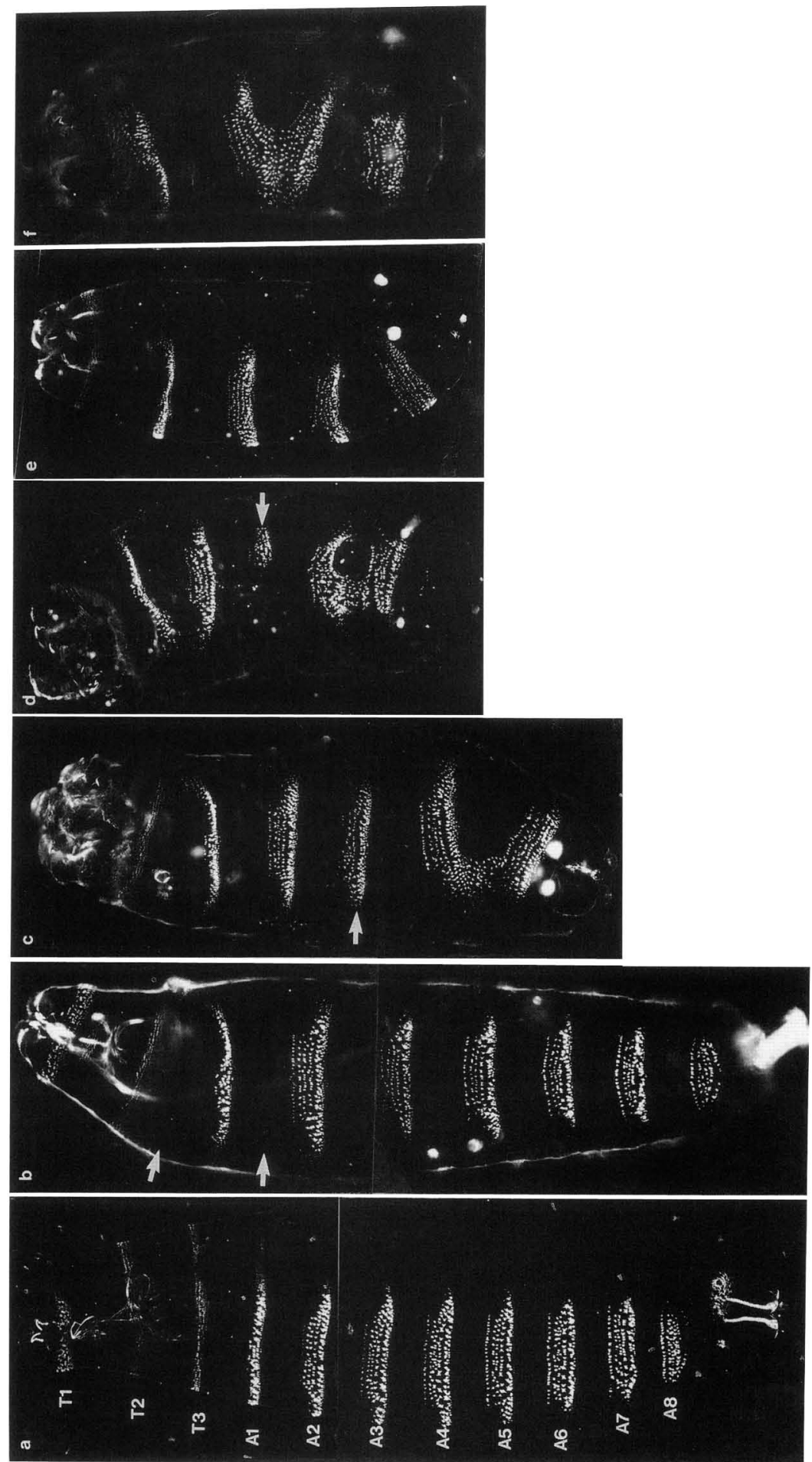

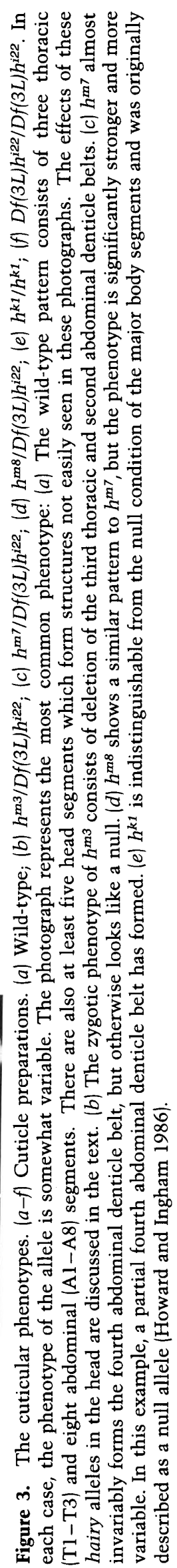


associated with the mandibular primordium, from which part of the ventral arms are formed (Jürgens et al. 1986). The phenotype of $h^{m 8}$ mutants is similar to that of $h^{m 7}$ inasmuch as the same regions are affected (Fig. $3 \mathrm{~d}$ ). However, the degree and frequency of the defects are very different so that $h^{m 8}$ mutant embryos generally show a far more severe and irregular phenotype. For example, deletions of the entire fourth abdominal denticle belt occur in $\$ 5 \%$ of $h^{m 7}$ animals but are very common in $h^{m 8}$, where $60 \%$ of the animals do not form any $\mathrm{A} 4$ denticles. In addition, fusions of the compound segments occur at a high frequency in $h^{m 8}$ but not in $h^{m 7}$ : the compound $\mathrm{T} 2 / \mathrm{T} 3$ and $\mathrm{A} 1 / \mathrm{A} 2$ segments fuse often $(35 \%)$ in $h^{m 8}$ but never in $h^{m 7}$; $\mathrm{A} 5 / 6$ and $\mathrm{A} 7 / 8$ are invariably fused in $h^{m 8}$ but only $17 \%$ of the time in $h^{m 7}$. The cuticle of $h^{k 1}$ homozygotes (Fig. 3e) is indistinguishable from the null condition of hairy (Fig. 3f) throughout the thoracic and abdominal segments. However, this is not so in the head region where the labral sense organ develops in $h^{k 1}$ animals. This structure, which is typically absent from hairy null animals, derives from the labrum (Jürgens et al. 1986), which is formed around the position of hairy region 0.

\section{Mapping the mutants}

All of the alleles were induced by X-rays and have been characterized cytologically (see Methods). We have located the positions of the breakpoints associated with these alleles on the DNA map of the hairy gene by Southern blotting. DNA prepared from flies heterozygous for the mutant allele and a polymorphic wild-type allele of hairy was digested with an appropriate restriction enzyme, electrophoresed, and blotted. The blot was probed with sequences covering $20.4 \mathrm{~kb}$ of DNA from $0.6 \mathrm{~kb}, 3^{\prime}$, to $19.8 \mathrm{~kb}, 5^{\prime}$ to the start of hairy transcription (see Fig. 4 and legend). The lesions are seen as changes in the mobility of restriction fragments detected by one of the probes. The three alleles $h^{m 3}, h^{m 7}$, and $h^{m 8}$ were all induced on the same chromosome and serve as controls for one another. Unfortunately, no controls are available for the other two alleles, $h^{k 1}$ and $h^{147}$. However, we are confident in assigning the lesions to the restriction fragment indicated because in situ hybridization to squashes of the polytene chromosomes of these mutants reveals that the breakpoint lies within the restriction fragment indicated (data not shown).

All of the lesions lie in the DNA, $5^{\prime}$ to the hairycoding sequence (summarized in Fig. 4g). The amount of $5^{\prime}$ hairy sequence remaining correlates with the severity of the mutant phenotype so that $h^{k 1}$, the strongest of the alleles, retains the least DNA - between 2.5 and $5.15 \mathrm{~kb}$ upstream from the transcription start site. The intermediate alleles $h^{m 8}$ and $h^{m 7}$ retain between 5.15 and 6.8, and 6.8 and $9.35 \mathrm{~kb}$, respectively. The weakest of the alleles, $h^{\mathrm{m} 3}$, retains the most DNA (between 9.35 and $10.8 \mathrm{~kb}$ ). The allele that has no effect on embryonic segmentation, $h^{r 47}$, is also X-ray induced, and the breakpoint associated with it lies between 14.9 and $19.8 \mathrm{~kb}, 5^{\prime}$ to the start site. This defines the maximum size of the $5^{\prime}$ region necessary for proper hairy expression during the blastoderm stage of development.

\section{Discussion}

Each of these four hairy mutants displays a unique pattern of expression in the blastoderm. We consider this to be due to regulation by part of the regulatory sequences that normally control hairy (it is extremely unlikely that all four of these breakpoints have generated neomorphic hairy alleles that fortuitously express hairy in particular parts of its normal pattern). This view is reinforced by the fact that the phenotypes of these alleles fall into a series and that this series correlates with the size of the regulatory region remaining.

Our data are consistent with a model of segmentation in which pair-rule periodicity forms as a consequence of pair-rule genes, including hairy, responding to distinct cues present in different parts of the blastoderm. These cues probably consist of the activities of the different gap (and possibly also primary coordinate) genes. It is simplest to assume that these cues are localized in the regions where the response occurs, so that they form a prepattern. It is not clear whether the borders of gap gene expression need to play a crucial role in organizing pairrule gene activity (Meinhardt 1986); nor does it seem necessary to invoke long-range reaction-diffusion mechanisms involving pair-rule genes (discussed in Akam 1987).

Figure 4. The location of the mutations in the hairy DNA. $(a-f)$ A series of Southern blots. In each case, the order of the DNA

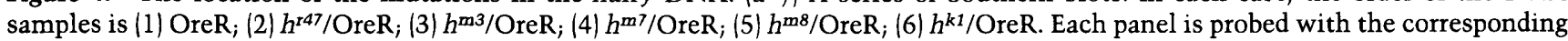
probe, as indicated on the map in $g$, e.g., a probed with sequences from the EcoRI fragment a. All of the digests are with EcoRI alone, except for $c$ and $d$, which are double digests with EcoRI and KpnI. $(g)$ Restriction map of the region. The sites of the mutations, as determined by the Southern blots, are shaded; the transcription unit is solid. The coordinate system has 0 at the start of transcription (C. Rushlow, pers. comm.) and differs from those used previously. Distances upstream of the start site are indicated in kb above the bar: (E) EcoRI; (K) KpnI. The wild-type stock is polymorphic, allowing the unique structure of the mutant chromosomes to be seen. The sizes of the fragments [(a) $4.9 \mathrm{~kb}$, (b) $4.1 \mathrm{~kb}$, (c) $1.45 \mathrm{~kb}$, (d) $2.55 \mathrm{~kb}$, (e) $1.65 \mathrm{~kb}$, (f) $2.65 \mathrm{~kb}$ ] are changed by these polymorphisms as follows: An additional EcoRI site in fragment a gives rise to two bands of 3.5 and $1.4 \mathrm{~kb}$, rather than one of $4.9 \mathrm{~kb}$ in $a$; the EcoRI sites between fragments $\mathrm{b}$ and $\mathrm{c}$ and $\mathrm{c}$ and $\mathrm{d}$ are missing so that one band of $9.75 \mathrm{~kb}$ is seen in $b$ and $c$ after digestion with EcoRI; when digested with EcoRI and KpnI, as in $d$, this band reduces to $9 \mathrm{~kb}$ due to an additional KpnI site. The mutant chromosomes, with the exception of $h^{k 1}$, contain a polymorphic EcoRI site in fragment $\mathrm{c}$ that gives two bands of 1.05 and $0.4 \mathrm{~kb}$, instead of one band of $1.45 \mathrm{~kb}$ upon digestion with EcoRI. These data extend previous maps of the hairy region (Holmgren 1985; Ish-Horowicz et al. 1985). 


\section{The response}

The simplest molecular mechanism for generating such a response to the prepattern would involve a set of dis- crete activating elements in the $5^{\prime}$ region of the hairy gene, each of which responded to a different signal and acted independently to activate the hairy promoter. There are precedents for this type of regulation in Dro-

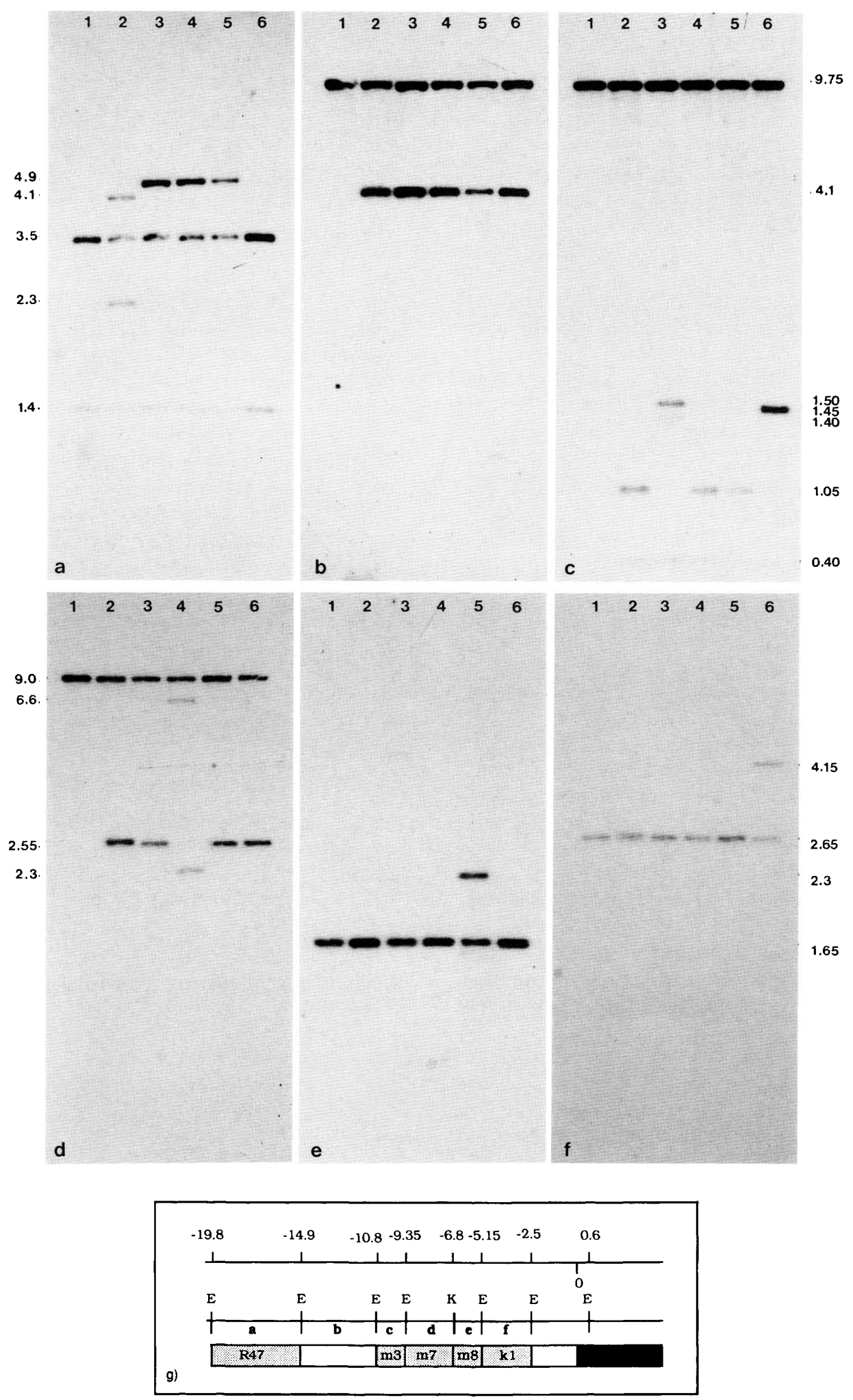

Figure 4. (See facing page for legend.) 
sophila genes (see, e.g., Geyer and Corces 1987). Our data do not establish that the hairy elements act independently, and other more complex mechanisms are conceivable. For example, it is possible there are a number of different elements that cooperate in generating an appropriate response and that the $5^{\prime}$ elements deleted in these mutants would not be sufficient to drive expression from the hairy promoter in the appropriate regions. It should be possible to distinguish between these possibilities by creating small interstitial deletions in the regulatory region using in vitro manipulation of the gene and P-element-mediated transformation. Whatever the precise mechanism, the mutations described here define a minimum number of elements required for normal hairy expression: one associated with region 0 between -2.5 and $-5.15 \mathrm{~kb}$; one with stripes 1 and 5 between -2.5 and $-6.8 \mathrm{~kb}$; one with stripe 2 between -5.15 and $-9.35 \mathrm{~kb}$; one with regions 6 and 7 between -6.8 and $-10.8 \mathrm{~kb}$; and one with regions 3 and 4 between -9.35 and $-19.8 \mathrm{~kb}$.

The regulation of the hairy gene contrasts with that of another pair-rule gene, $f t z$. In this case, a small $5^{\prime}$ region of $\leqslant 1 \mathrm{~kb}$ is sufficient to drive periodic expression of the gene (Hiromi and Gehring 1987). Although it remains possible that this regulatory region responds to multiple cues, it seems more likely that it responds to a simple periodic cue (Edgar et al. 1986; Hiromi and Gehring 1987). The $\mathrm{ftz}$ pattern is affected by mutations at the primary pair-rule genes hairy, runt, and even-skipped (Carroll and Scott 1986; Howard and Ingham 1986; Frasch and Levine 1987), and it seems reasonable to propose that these genes act as intermediaries between $f t z$ and the prepattern (Howard and Ingham 1986; Ingham and Martinez-Arias 1986; Martinez-Arias and White 1988). Our data suggest that hairy is involved in decoding the prepattern. It is interesting to note that allele-specific differences in the severity of the different regions affected by runt have been reported (Gergen and Wieschaus 1986), and it may be that runt and eve also perform decoding tasks.

The observation of the sequence of development of stripe 5 in $h m 8$ suggests that the patterns observed do not form by early general activation of hairy, followed by later local repression, but argue more for specific local activations. This contrasts with the view of global activation followed by local repression suggested by Edgar et al. (1986). However, the observation of broader regions of expression in $h^{m 3}$ may reflect a later repression involved in refining the hairy pattern. The hairy stripes are broadened in animals mutant at the pair-rule gene runt (Ingham and Gergen 1988), and there may be a runt responding element inactivated in $h^{\mathrm{m} 3}$. We note that our screens would not recover all derepression mutants because ectopic hairy expression can be lethal (IshHorowicz and Pinchin 1987).

Alternatively, both the broadened expression in $h^{m 3}$ and the low level of apparently uniform expression in $h^{m 7}$ may be due to the sequences bought into proximity to hairy by the rearrangement. These two alleles produce the most uniform cuticle patterns, whereas the other two alleles, $h^{m 8}$ and $h^{k 1}$, produce far more variable cuticle patterns that are more typical of the null condition. Thus, it seems that $h^{m 7}$ and $h^{m 3}$ may provide a small amount of hairy function outside the regions where high levels of expression are observed; and this allows the cuticular pattern to develop in a more regular way.

\section{The signals}

The signals that hairy is responding to are probably generated by the coordinate and gap classes of segmentation genes that affect the pattern of expression of the pairrule genes (Ingham et al. 1985a; Mohler and Wieschaus 1985; Carroll and Scott 1986; Carroll et al. 1986; Harding et al. 1986; Howard and Ingham 1986; Ingham et al. 1986; Macdonald and Struhl 1986; Frasch and Levine 1987; Frohnhofer and Nüsslein-Volhard 1987; Mahoney and Lengyel 1987; Mlodzik et al. 1987; NüssleinVolhard et al. 1987; Petschek et al. 1987). It is possible that the cues hairy sees consist of both gap and coordinate activities. Alternatively, there might be no direct participation of the coordinate gene products and the signals may consist only of gap gene products. It seems that hairy stripes 3 and 4; which are missing in $h m 3$ mutants, are under the influence of the Krüppel $(\mathrm{Kr})$ gene (Ingham et al. 1986; Howard 1988), and we propose that the regulatory sequences between -9.35 and -14.9 respond to a signal involving $K r$ activity. It may well be that the $K r$ protein, which contains a nucleic acid binding finger domain (Rosenberg et al. 1986), interacts directly with this upstream region. Alternatively, the region may be responding to $K r$-dependent factors that do not contain $K r$ protein.

\section{Conclusion}

We favor a two-step model for the generation of the periodic patterns of pair-rule gene expression: First, a prepattern is formed by the coordinate and gap genes, which is then decoded by hairy (and the other primary pair-rule genes). Our results point to this decoding function occurring at the level of transcription and suggest that there are several distinct 5 ' elements involved. The precise nature of the molecular mechanism that operates to achieve this regulation of hairy is not clear. In the simplest case, a set of independently acting enhancer elements would respond to the different cues making up the prepattern.

\section{Methods}

The alleles $h^{r 47}, h^{m 3}$, and $h^{k 1}$ are X-ray-induced rearrangements and have been described previously (Ingham et al. 1985b), where it was noted that $h^{m 3}$ had an unusual region-specific phenotype and a maternal effect. The phenotype we describe here is the zygotic one. We have examined the other hairy alleles described here for maternal effects and find none. The alleles $h^{m 7}$ and $h^{m 8}$ were isolated for failure to complement the visible adult phenotype of $h^{2}$ in an X-ray mutagenesis in the manner described previously for $h^{m 3}$ (Ingham et al. 1985). The allele $h^{m 7}$ 
is an inversion [ $\operatorname{In}(3 \mathrm{~L}) 66 \mathrm{D} 6-67 \mathrm{D} 8]$. The allele $h^{\mathrm{m} 8}$ is cytologically normal and is therefore presumably associated with a small rearrangement. Tissue in situ hybridization was performed essentially as described by Ingham et al. (1985a), except that the incubation of the slides in $2 \times$ SSC during the pretreatment was at room temperature and the washes in $50 \%$ formamide, $1 \times$ salts (Ingham et al. 1985a), and $50 \mathrm{~mm} \mathrm{2-mercap-}$ toethanol. Sometimes, washing was in aqueous buffers with no formamide [ $1 \times 60 \mathrm{~min}$ in $4 \times \mathrm{SSC}, 0.1 \%$ dithiothreitol (DTT); $4 \times 60 \mathrm{~min}$ in $4 \times \mathrm{SSC}, 0.01 \%$ DTT at room temperature; RNase A treatment, as described previously; $2 \times 10 \mathrm{~min}$ in $0.1 \times \mathrm{SSC}$ at $50^{\circ} \mathrm{C}$; overnight wash in $4 \times \mathrm{SSC}, 0.1 \% \mathrm{DTT}$ at $50^{\circ} \mathrm{C}$. Probes were synthesized using T7 polymerase and either $\left[\alpha^{-35}\right.$ S]UTP (Amersham) to a final sp. act. of $\sim 1.2 \times 10^{9} \mathrm{dpm} / \mu \mathrm{g}$ or $\left[{ }^{3} \mathrm{H}\right]$ UTP and $\left[{ }^{3} \mathrm{H}\right]$ ATP (Amersham) to a final sp. act. of $\sim 1.5 \times 10^{8} \mathrm{dpm} / \mu \mathrm{g}$. The template used to make the hairy probe was a cDNA derivative, $p \operatorname{ch} \Delta 1$, in which $\sim 500$ bp of repetitive sequence have been deleted (A. Taylor and D. Ish-Horowicz, pers. comm.): the $f t z$ template contained $\sim 2 \mathrm{~kb}$ of genomic sequence. DNA preparation and Southern transfer hybridization were by standard techniques.

\section{Acknowledgments}

We would like to thank David Ish-Horowicz, in whose laboratory this study was initiated, and Mike Levine and Gary Struhl for supporting its completion. We thank Anita Taylor and David Ish-Horowicz for the gift of the template clone pch $\Delta 1$. Paul Macdonald and Gary Struhl gave invaluable criticism of the manuscript. K.H. is a Lucille P. Markey Visiting Fellow. This work was supported by the Medical Research Council, the Imperial Cancer Research Fund, the American Cancer Society, and the Howard Hughes Medical Research Institute.

\section{References}

Akam, M.E. 1987. The molecular basis for metameric pattern in the Drosophila embryo. Development 101: 1-22.

Carroll, S. and M.P. Scott. 1985. Localization of the fushitarazu protein during Drosophila embryogenesis. Cell 45: 47-57.

-1986. Zygotically active genes that affect the spatial expression of the fushi tarazu segmentation gene during early Drosophila embryogenesis. Cell 45: 113-126.

Carroll, S.B., G.M. Winslow, T. Schupbach, and M.P. Scott. 1986. Maternal control of Drosophila segmentation gene expression. Nature 323: 278-280.

Edgar, B., M.P. Weir, G. Schubiger, and T. Kornberg. 1986. Repression and turnover pattern fushi tarazu RNA in the early Drosophila embryo. Cell 47: 747-754.

Foe, V.E. and B.M. Alberts. 1983. Studies of nuclear and cytoplasmic behavior during the five mitotic cycles that precede gastrulation in Drosophila embryogenesis. I. Cell Biol. 61: $31-70$.

Frasch, M. and M. Levine. 1987. Complementary patterns of even-skipped and fushi-tarazu expression involve their differential regulation by a common set of segmentation genes in Drosophila. Genes Dev. 1: 981-995.

Frasch, M., T. Hoey, C. Rushlow, H. Doyle, and M. Levine. 1987. Characterization and localization of the even-skipped protein of Drosophila. EMBO J. 6: 749-760.

Frohnhofer, H.G. and C. Nüsslein-Volhard. 1987. Maternal genes required for the anterior localization of bicoid activity in the embryo of Drosophila. Genes Dev. 1: 880-890.

Gaul, U. and H. Jackle. 1987. How to fill a gap in the Droso- phila embryo. Trends Genet. 3: 127-131.

Gergen, J.P. and E. Wieschaus. 1986. Dosage requirements for runt in the segmentation of Drosophila embryos. Cell 45: 289-299.

Geyer, P.K. and V.G. Corces. 1987. Separate regulatory elements are responsible for the complex pattern of tissue-specific and developmental transcription of the yellow locus of Drosophila melanogaster. Genes Dev. 1: 996-1004.

Hafen, E., A. Kuroiwa, and W.J. Gehring. 1984. Spatial distribution of transcripts from the segmentation gene fushi tarazu during Drosophila embryonic development. Cell 37: 833841.

Harding, K., C. Rushlow, H.J. Doyle, T. Hoey, and M. Levine. 1986. Cross-regulatory interactions among pair-rule genes in Drosophila. Science 233: 953-959.

Hiromi, Y. and W.J. Gehring. 1987. Regulation and function of the Drosophila segmentation gene fushi tarazu. Cell 50: $963-974$.

Holmgren, R. 1985. Cloning sequences from the hairy gene of Drosophila. EMBO J. 3: 569-573.

Howard, K. 1988. The generation of periodic pattern during Drosophila embryogenesis. Development Suppl. (in press).

Howard, K. and P. Ingham. 1986. Regulatory interactions between the segmentation genes fushi tarazu, hairy and engrailed in the Drosophila blastoderm. Cell 44: 949-957.

Ingham, P.W. and J.P. Gergen. 1988. Interactions between the pair-rule genes runt, hairy, even-skipped and fushi tarazu and the establishment of periodic pattern in the Drosophila embryo. Development Suppl. (in press).

Ingham, P.W. and A. Martinez-Arias. 1986. The correct activation of Antennapedia and bithorax complex genes requires the fushi tarazu gene. Nature 324: 592-597.

Ingham, P., D. Ish-Horowicz, and K. Howard. 1986. Correlative changes in homeotic and segmentation gene expression in Krüppel mutant embryos of Drosophila. EMBO f. 5: 16591665.

Ingham, P., K.R. Howard, and D. Ish-Horowicz. 1985a. Transcription pattern of the Drosophila segmentation gene hairy. Nature 318: 493-445.

Ingham, P., S.M. Pinchin, K.R. Howard, and D. Ish-Horowicz. 1985b. Genetic analysis of the hairy gene in Drosophila. Genetics 111: 463-486.

Ish-Horowicz, D. and S.M. Pinchin. 1987. Pattern abnormalities induced by ectopic expression of the Drosophila gene hairy are associated with repression of $f t z$ transcription. Cell 51: $405-415$.

Ish-Horowicz, D., K.R. Howard, S.M. Pinchin, and P.W. Ingham. 1985. Molecular and genetic analysis of the hairy locus in Drosophila. Cold Spring Harbor Symp. Quant. Biol. 50: 135-144.

Jürgens, G., R. Lehmann, M. Schardin, and C. Nüsslein-Volhard. 1986. Segmental organization of the head in the embryo of Drosophila melanogaster. Wilhelm Roux's Arch. Dev. Biol. 195: 359-377.

Kilcherr, F., S. Baumgartner, D. Boop, E. Frei, and M. Noll. 1986. Isolation of the paired gene of Drosophila and its spatial expression during early embryogenesis. Nature 321: 493-499.

Macdonald, P. and G. Struhl. 1986. A molecular gradient in early Drosophila embryos and its role in specifying the body pattern. Nature 324: 537-545.

Macdonald, P., P. Ingham, and G. Struhl 1986. Isolation, structure and expression of even-skipped: A second pair-rule gene of Drosophila containing a homeobox. Cell 47: 721-734.

Mahoney, P. and J. Lengyel. 1987. The zygotic segmentation gene tailless alters the blastoderm fate map of the Droso- 
phila embryo. Dev. Biol. 122: 464-470.

Martinez-Arias, A. and R.A.H. White. 1988. Ultrabithorax and engrailed expression in Drosophila embryos mutant for segmentation genes of the pair-rule class. Development 102: $325-338$.

Meinhardt, H. 1986. Hierarchical inductions of cell states: A model for segmentation in Drosophila. J. Cell. Sci. 4: 357381.

Mlodzik, M., C.M. DeMontrion, Y. Hiromi, H.M. Krause, and W.J. Gehring. 1987. The influence on the blastoderm fate map of maternal-effect genes that affect the antero-posterior pattern in Drosophila. Genes Dev. 1: 603-614.

Mohler, J. and E.F. Wieschaus. 1985. Bicaudal mutations of Drosophila melanogaster: Alteration of blastoderm cell fate. Cold Spring Harbor Symp. Quant. Biol. 50: 105-111.

Nüsslein-Volhard, C. and E. Wieschaus. 1980. Mutations affecting segment number and polarity in Drosophila. Nature 287: 795-801.

Nüsslein-Volhard, C., H.G. Frohnhofer, and R. Lehmann. 1987. Determination of anteriorposterior polarity in Drosophila. Science 238: 1675-1681.

Nüsslein-Volhard, C., H. Kluding, and G. Jürgens. 1985. Genes affecting the segmental subdivision of the Drosophila embryo. Cold Spring Harbor Symp. Quant. Biol. 50: 145-154.

O'Farrell, P. and M.P. Scott. 1986. Spatial programming of gene expression in early Drosophila embryogenesis. Annu. Rev. Cell Biol. 2: 49-80.

Petschek, J., N. Perrimon, and A.P. Mahowald. 1987. Regionspecific defects in 1(1)giant embryos of Drosophila melanogaster. Dev. Biol. 119: 175-189.

Rosenberg, U.B., C. Schroder, A. Preiss, A. Kienlin, S. Cote, I. Riede, and H. Jackle. 1986. Structural homology of the product of the Drosophila Kruppel gene with Xenopus transcription factor IIIA. Nature 329: 336-339.

Scott, M.P. and S. Carroll. 1987. The segmentation and homeotic gene network in early Drosophila development. Cell 51: 689-698.

Stern, C. 1968. Genetic mosaics and other essays. Harvard University Press, Cambridge, Massachusetts.

Turing, A.M. 1952. The chemical basis of morphogenesis. Philos. Trans. Roy. Soc. B. 641: 37-72.

Weir, M.P. and T. Kornberg. 1985. Patterns of engrailed and fushi tarazu transcripts reveal novel intermediate stages in Drosophila segmentation. Nature 318: 433-439. 


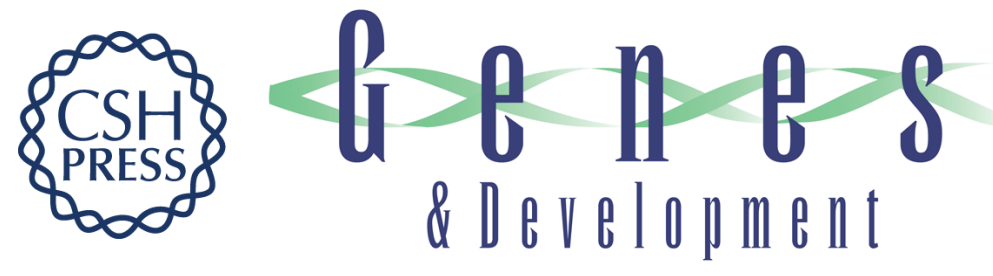

\section{Region-specific alleles of the Drosophila segmentation gene hairy.}

K Howard, P Ingham and C Rushlow

Genes Dev. 1988, 2:

Access the most recent version at doi:10.1101/gad.2.8.1037 $\begin{array}{ll}\text { References } & \begin{array}{l}\text { This article cites } 41 \text { articles, } 11 \text { of which can be accessed free at: } \\ \text { http://genesdev.cshlp.org/content/2/8/1037.full.html\#ref-list-1 }\end{array}\end{array}$

License

Email Alerting Service

Receive free email alerts when new articles cite this article - sign up in the box at the top right corner of the article or click here.

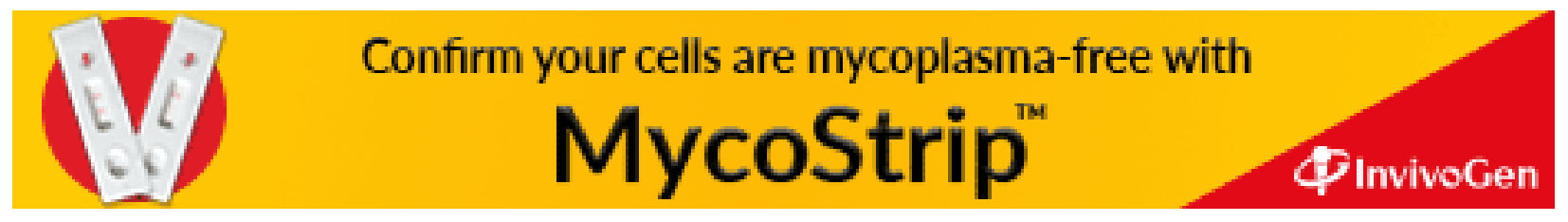

